\title{
Original Research Article \\ Prevalence and analysis of abnormal Pap smear: Prospective study of 752 patients in a tertiary care hospital of South India
}

\author{
Singh A. ${ }^{1}$, N. Madhavi ${ }^{2}$, Sukhavasi.$^{3}$ \\ ${ }^{1}$ Dr. Amrita Singh, Assistant Professor, ${ }^{2}$ Dr. N. Madhavi, Professor and HOD, ${ }^{3}$ Dr. Chinmayee Sukhavasi, PG Student, all \\ authors are affiliated with Department of Obstetrics \& Gynecology; Kamineni Institute of Medical Sciences (KIMS), Narket- \\ 05.pally, Nalgonda District, T.G, India.
}

Corresponding Author: Dr. Amrita Singh, Assistant Professor, Department of OBG, KIMS, Narketpally, Nalgonda District, T.G, INDIA. Email id: singh.amrita86@gmail.com

\begin{abstract}
Background: Cancer of the cervix is the third most common cancer in women. In India and other developing countries cervical cancer is the leading cause of morbidity and mortality. Cancer cervix is readily preventable, and can be diagnosed at the pre-invasive stage with adequate and repetitive cytological screening with Papanicolaou (Pap) smears. Most women never undergo a cervical Pap smear screening. The objective of this study is to determine the prevalence of abnormal cervical epithelial lesions. Materials and Methods- This was a prospective study of 752 conventional cervical Pap smears reported from the Department of Pathology and gyaenecology, KIMS Medical College Narketpally. The time period was from Jan 2018 to June 2018. The abnormal Pap smears were assessed according to the Bethesda system 2001. Results: A total of 752 Pap smears were collected from patients aging 18 to 74 years old. The cervical smears were classified according to the Bethesda system: 377 (50.13\%) were negative, $313(41.62 \%)$ were benign cellular changes and $19(2.52 \%)$ were abnormal (squamous intraepithelial lesion) (SIL), 43 (5.71\%) were inadequate. Amongst the abnormal smear, percentage of ASCUS (36.8\%) (7 out of 19 smears), LSIL (52.6\%) (10 out of 19 smears) were more common and incidence of the cervical cancer among these samples was $(0.13 \%)$ ( 1 out of 752$)$. Conclusion: Preinvasive and malignant lesions of cervix can be easily picked up with simple pap smear test. The Epithelial cell abnormality was found in $2.52 \%$ in our set up.
\end{abstract}

Key words: Pap smear, Cervical cancer, Tertiary care hospital

\section{Introduction}

Cancer is a major public health problem both in our country and worldwide because of its disease burden, fatality, and tendency toward increased incidence [1]. Globally, cervical cancer is the second most prevalent cancer among all populations and third most common type of cancer after breast and lung cancers among women [2]. The global burden of cervical cancer is disproportionately high in developing countries. India, which accounts for one sixth of the world's population, also bears one fifth of the world's cervical cancer burden [3]. Women in these countries usually present to the clinic only when they have symptoms, such as pain, discharge, and/or abnormal bleeding [4].

In India, late presentation is attributed to many factors, notably a lack of knowledge and awareness of and a lethargic attitude toward safe health practices. Sexually transmitted Human Papilloma Virus is the most important

Manuscript received: $10^{\text {th }}$ September 2018

Reviewed: $20^{\text {th }}$ September 2018

Author Corrected: $26^{\text {th }}$ September 2018

Accepted for Publication: $30^{\text {th }}$ September 2018

Obsgyne Review: Journal of Obstetrics and Gynecology risk factor for intraepithelial neoplasia and invasive cervical cancer. The incidence of ca cervix is more in lower socioeconomic status who fails to carry out regular health checkup due to financial inadequacy.

Invasive cervical malignancy is preceded by premalignant cervical epithelial lesions of different grades which are termed as cervical intraepithelial neoplasia (CIN). According to Bethesda system, preinvasive cervical lesions are classified into two groups: Low-grade Squamous Intraepithelial Lesion (LSIL) and High-grade Squamous Intraepithelial Lesion (HSIL) [5]. The Bethesda System (TBS) for reporting the results of cervical cytology was developed as a uniform system of terminology that could provide clear guidance for clinical management.

Cancer of the cervix can be prevented by intercepting it at the preinvasive stage. In general, in countries where Pap smear screening is routine, it is recommended that females who have had sex should seek regular Pap smear

Available online at: www.medresearch.in 67 | P a g e 
testing. Guidelines on frequency vary from every three to five years. If results are abnormal, and depending on the nature of the abnormality, the test may need to be repeated in six to twelve months [6]. The role of the Pap smear as a cancer screening tool for the cervix has been substantiated by several studies in the last 50 years

Pap smear is a simple cost-effective screening test. Along with gynecological examination if used helps in detecting early precursor lesions of cancer cervix. When these lesions are treated adequately and timely, it helps in reducing the incidence of ca cervix $[7,8]$. Though Pap smear is a routine screening test, the overall sensitivity in detection of high grade squamous intraepithelial lesion (HSIL) is $70-80 \%$ [9]. Intensive screening programmes carried out in various developed countries show a striking reduction in mortality and morbidity from cancer of cervix [10]. The present study is conducted to study the early diagnosis of preneoplastic and neoplastic lesions of uterine cervix and to know the age incidence, which would help in reducing the mortality and morbidity due to ca cervix. The study was also conducted to find the incidence of various abnormal pap smear at our setup.

\section{Material and Methods}

Place of study: This study was conducted in the Department of Ostetrics and Gyaenocology at Kamineni Institute of Medical Sciences (KIMS), Narketpally.

Type of study: It was a Prospective study done over a period of six months from Jan to June 2018.

Sample size: The study was done on 752 patients. Pap smears prepared from patients presenting with complaints like vaginal discharge, post-coital bleeding, intermenstrual bleeding, dyspareunia and pain lower abdomen. Relevant history of illness was obtained from the patient and recorded on the proforma.

\section{Results}

The present study included 752 female patients.

\section{Original Research Article}

Sampling Method and Collection: All sexually active women between 21 to 65 years of age attending the gynecology OPD of KIMS Narketpally was included after the informed consent. Detailed history was taken about their complaints like vaginal discharge, itching, intermenstrual bleeding, post coital bleeding, postmenopausal bleeding.

It was ensured that no local douche, antiseptic cream and no local internal examination was done on the day of test. The patient was placed in dorsal lithotomy position and a Cusco's bivalve speculum was introduced through vagina and cervix was visualized. The longer projection of the Ayre's spatula was placed in the cervix near squamocolumnar junction and rotated through $360^{\circ}$. The cellular material thus obtained was quickly, but gently smeared on a clean glass slide. The glass slide was then immediately put into the jar containing $95 \%$ ethyl alcohol which acted as a fixative.

The prepared smears were then stained according to Papanicolaou's technique. The cytological interpretation of the smears was made according to the New 2001 Bethesda system.

\section{Inclusion Criteria}

1. All sexually active women between 21 to 65 years of age attending the gynecology OPD

\section{Exclusion Criteria:}

1. Sexually not active.

2. Women with diagnosed cervical cancer.

3. History of vaginal medications within last 7 days.

4. Menstruating woman.

5. Women whose hysterectomy had already been done

Data are presented as frequency (\%) using descriptive analysis

Table-1: Age wise distribution of patients with Pap smear.

\begin{tabular}{|c|c|c|}
\hline Sr No & Age & No of cases \\
\hline 1 & $18-20$ & 10 \\
\hline 2 & $21-30$ & 322 \\
\hline 3 & $31-40$ & 249 \\
\hline 4 & $41-50$ & 130 \\
\hline 5 & $51-60$ & 27 \\
\hline 6 & $61-70$ & 12 \\
\hline 7 & $71-80$ & 2 \\
\hline
\end{tabular}


Maximum number of patients (42.8\%) were in the age group of 21-30 years (third decade) followed by $33.1 \%$ in fourth, $17.3 \%$ in fifth, $3.6 \%$ in sixth decade and $1.6 \%$ in seventh decade and rest in other age groups (table 1 ). The youngest patient was of age 18 years and oldest was 75 years old

Table- 2 : Chief complaints.

\begin{tabular}{|c|c|c|}
\hline Complaints & Number of patients & Percentage (\%) \\
\hline Discharge per vaginum & 432 & 57.44 \\
\hline Pain in lower abdomen & 156 & 20.74 \\
\hline Intermenstrual bleeding & 75 & 9.97 \\
\hline Dyspareunia & 40 & 5.31 \\
\hline Postcoital bleeding & 37 & 4.92 \\
\hline Postmenopausal bleeding & 12 & 1.59 \\
\hline TOTAL & $\mathbf{7 5 2}$ & \\
\hline
\end{tabular}

The most common presenting complaint was discharge per vaginum with pain abdomen present in $432(57.44 \%)$ patients. History of pain in the lower abdomen was also present in 156 (20.74\%), inter menstrual bleeding in 75 (9.97\%), and 40 $(5.31 \%)$ patients had complaint of dyspareunia. Post-coital bleeding was the chief complaint in 37 (4.92\%) patients. $12(1.59 \%)$ patients presented with post menopausal bleeding.

Table- 3: Categorization of cytodiagnosis.

\begin{tabular}{|c|c|}
\hline & Pap smear report \\
\hline Negative for intraepithelial lesion or malignancy & 384 \\
\hline Benign cellular changes & 313 \\
\hline Squamous intraepithelial lesion including carcinoma & 12 \\
\hline Inadequate & 43 \\
\hline Total & $\mathbf{7 5 2}$ \\
\hline
\end{tabular}

The cervical smears were classified according to the Bethesda system: $384(50.13 \%)$ were negative, $313(41.62 \%)$ were benign cellular changes and 19 (2.52\%) were abnormal (squamous intraepithelial lesion) (SIL), 43 (5.71\%) were inadequate (table 3)

Table-4: Distribution of cases under various diagnostic categories in Pap smear and the mean age of its presentation

\begin{tabular}{|c|c|c|}
\hline Abnormal Pap Smear Result & Number (\%) & Age Mean (Range) \\
\hline ASCUS & $7(36.8 \%)$ & $40(24-50)$ \\
\hline LSIL & $10(52.6 \%)$ & $38.4(24-55)$ \\
\hline HSIL & $1(5.2 \%)$ & 42 \\
\hline SCC & $1(5.2 \%)$ & 50 \\
\hline Total & $\mathbf{1 9}$ & \\
\hline
\end{tabular}

The Abnormal smears (SIL) can be separated into ASCUS (36.8\%) (7 out of 19 smears), LSIL (52.6\%) (10 out of 19 smears), HSIL (5.2\%) (1 out of 19 smears), carcinoma (5.2\%) (1out of 19 smears) and incidence of the cervical cancer among these samples was $(0.13 \%)$ (1out of 752$)$

Mean age of cases with low grade squamous intraepithelial lesion (LSIL) was 38.4 years and those with HSIL and invasive carcinoma were 42 years and 50 years respectively. There was sequential progression in the development of LSIL to HSIL to invasive carcinoma as the age advances. The average age of patients for all the epithelial abnormalities was 43.25 years. 


\section{Discussion}

The incidence of cervical cancer has decreased more than $50 \%$ in the past 30 years because of widespread screening with cervical cytology. In 1975, the rate was 14.8 per 100,000 women in the United States and by 2006, it had been reduced to 6.5 per 100,000 women. Mortality from the disease has undergone a similar decrease $[11,12,13]$. Considering the efficacy of Pap smear cytology in preventing cervical cancer, it is advocated that it should be initiated in all women at the age of 21 years [14].

Cancer cervix is considered to be an ideal gynaecological malignancy for screening as has a long latent phase during which it can be detected as identifiable and treatable premalignant lesions which precede the invasive disease and the benefit of conducting screening for carcinoma cervix exceeds the cost involved [15].

Cervical cytology is currently widely used as the most effective cancer screening modality. Objective data from hospital-based studies are required in order to detect the efficiency of the screening test. This study contributes to assessing current levels of cervical screening in the tertiary teaching hospital in KIMS, Narketpally. In our study more number of patients were in the third decade [42.8\%]. But a major percentage was also in the fourth decade [33.1\%]. This study reveals that Pap smear cytology is still delayed by many years in the majority of women of this country. The physicians or healthcare professionals are not requesting Pap smear testing and not educating people about the benefits of the Pap smear test [16]. More education programs should be created to increase the awareness of the benefit of cervical Pap smears.

In our study, mean age of patients with LSIL was found to be 38.4 years, and those with HSIL were 42 yrs and invasive carcinoma were 50 years. Elhakeem et al. also noted a progressive increase in development of LSIL to invasive carcinoma with increasing age. LSIL had peak between 20-29 years, HSIL between 30-39 years and invasive carcinoma had peak incidence in age group of 50-59 years [17].

Afrakhteh et al found mean age of patients with LSIL, HSIL and invasive cancer to be $37.7,41.7$ and 54.5 years, respectively. The results are comparable with our present study [18]. Vaginal discharge was the most common presenting complaint in our study. Other studies also reported similar findings $[19,20]$. Also we emphasize the significance of vaginal discharge and its association with neoplastic changes in the cervix. The results correspond with many previous studies [21, 22, 23].
The Epithelial Cell Abnormality (ECA) rate, that is the total of ASCUS, ASC-H, LSIL, HSIL, AGC and carcinoma diagnosis varied between 1.5 and $12.60 \%$ in various studies. The percentage of epithelial abnormalities is $2.3 \%$ to $6.6 \%$, in the US, from $1.6 \%$ to $7.9 \%$ in the Middle East, and 1.87 to $5.9 \%$ in India [24]. The ECA rate of $2.52 \%$ in our study was comparable to those reported in literature [25]. Few studies have reported higher incidences of ECA because they have screened only symptomatic women [26]. But here we have screened all sexually active women meeting our inclusion criteria and hence may be the incidence is low.

Epithelial cell abnormality is most common in $4^{\text {th }}$ decade, since our study group contained more patients in third decade and hence low incidence of ECA. This could also be due to lack of awareness programmes for pap smear screening programmes.

Also, people reported to the hospital only when they had vaginal discharge or abdominal pain and then hardly ever revert back for repeat Pap smear after subsidence of inflammation. May be if we create awareness among professionals and patients regarding the need for repeat pap smear we could pick more ECA patients.

\section{Conclusion}

Cervical cancer is the second most common cause of cancer mortality among women in India; however, it is a largely preventable disease [27].

While reviewing all the results, it is concluded that premalignant and malignant lesions of cervix are not uncommon in our set up. Cervical cytology by Pap smear is a simple, safe and effective test to detect premalignant and malignant lesions of cervix at an early stage, and thus help the clinicians in early and more efficient management of the patients.

A good centrally organized cytological cervicovaginal screening program, implemented by the public sector, is recommended. Visual inspection aided by application of acetic acid is an alternative to cytology screening, yet new techniques such as HPV DNA testing can be used to identify cervical lesions without reliance on cytology [28].

We would also like to stress upon the need for repeat pap smear of inflammatory smears once the infection subsides, which would help us to pick more ECA cases.

Potential benefits: The information obtained from this study could help the institution to know about the

Available online at: www.medresearch.in $70 \mid \mathrm{P}$ a g e 
prevalence of various abnormal smears in this area and accordingly screening programmes can be emphasized and can further be used for various other research purposes.

\section{Author Contributions}

Conception and design: Amrita Singh, Administrative support: $\mathrm{N}$ Madhavi, Provision of study material or patients: Amrita Singh, Collection and assembly of data: Amrita singh, Chinmayee Sukhavasi, Asma, Data analysis and interpretation: Amrita Singh, N Madhavi, Manuscript writing: All authors, Final approval of manuscript: All authors, Accountable for all aspects of the work: All authors

Funding: Nil, Conflict of interest: Nil

Permission from IRB: Yes

\section{References}

1. Şahin ZA, Tan M, Polat H. Hopelessness, depression and social support with end of life Turkish cancer patients. Asian Pac J Cancer Prev. 2013;14(5):2823-8.

2. Sogukpinar N, Saydam BK, Can HO, et al. Assessment of cervical cancer risk in women between 15 and 49 years of age: case of Izmir. Asian Pac J Cancer Prev. 2013; 14 (3): 2119-25.

3. Barillot I, Horiot JC, Maingon P, et al. Impact on treatment outcome and late effects of customized treatment planning in cervix carcinomas: baseline results to compare new strategies. Int J Radiat Oncol Biol Phys. 2000 Aug 1;48(1):189-200.

4. Patel M.M, Pandya A.N, Modi J. Cervical papsmear study and its utility in cancer screening, to specify the strategy for cervical cancer control. National Journal of Community Medicine 2011; vol 2, issue1.

5. Solomon D, Davey D, Kurman R, et al. The 2001 Bethesda System: terminology for reporting results of cervical cytology. JAMA. 2002 Apr 24; 287 (16): 2114-9.

6. Saslow et al. American Cancer Society, American Society for Colposcopy and Cervical Pathology, and American Society for Clinical Pathology Screening Guidelines for the Prevention and Early Detection of Cervical Cancer. Journal of Lower Genital Tract Disease 2012; Vol 16, No. 3: 175 -204,.

7. Jonathan S.B. Berek and Novak's Gynaecology.14th ed. Philadelphia: Lippincott William Wilkins 2006; p.569-575.

\section{Original Research Article}

8. Leopold K.The New Bethesda System for Reporting Results of Smears of Uterine cervix. Journal of National Cancer Institute 1990; 82(12):988-990.

9. Maryem A, Ghazala M, Arif, H.A, Tamkin K. Smear Pattern and Spectrum of Premalignant and Malignant Cervical Epithelial Lesions in Postmenopausal Indian Women: A Hospital Based Study. Diagnostic Cytopathology 2011; 40(11):976-983.

10. Ferlay J, Shin HR, Bray F, et al. Estimates of worldwide burden of cancer in 2008: GLOBOCAN 2008. Int J Cancer. 2010 Dec 15;127(12):2893-917. doi: 10. 1002/ijc.25516. DOI:10.1002/ijc. 25516

11. Herrero R. Epidemiology of cervical cancer. J Natl Cancer Inst Monogr 1996; 21:1-6.

12. Mango LJ, Radensky P. Neural network-assisted ("NNA") analysis of cervical smears: pooled effectiveness results and economic analysis. Prim Care Update $\mathrm{Ob}$ Gyns. 1998 Jul 1;5(4):162-163.

13. van der Graaf Y, Klinkhamer PJ, Vooijs GP. Effect of population screening for cancer of the uterine cervix in Nijmegen, The Netherlands. Prev Med. 1986 Nov;15(6): $582-90$.

14. ACOG Committee on Practice Bulletins-Gynecology, The American College of Obstetrician and Gynecologists. ACOG practice bulletin clinical management guidelines for obstetrician-gynecologists. Number 40, November 2002. Obstet Gynecol. 2002 Nov; 100 (5 Pt 1): 104550.

15. Kerkar RA, Kulkarni YV. Screening for cervical cancer: An overview. J Obstet Gynecol India 2006;56: 115-22.

16. Gamarra CJ, Paz EP, Griep RH. [Knowledge, attitudes and practice related to Papanicolaou smear test among Argentina's women]. Rev Saude Publica. 2005 Apr;39 (2): 270-6. Epub 2005 May 9. DOI:/S0034-8910200 5000 200019

17. Elhakeem HA, Al-Ghamdi AS, Al-Maghrabi JA. Cytopathological pattern of cervical Pap smear according to the Bethesda system in Southwestern Saudi Arabia. Saudi Med J. 2005 Apr;26(4):588-92.

18. Afrakhteh M, Khodakarami N, Moradi A, Alavi E, Shirazi FH. A study of 13315 papanicolaou smear diagnoses in Sohada hospital. J Fam Reprod Health 2007; $1: 75-9$. 
19. Pradhan B, Pradhan SB, Mital VP. Correlation of PAP smear findings with clinical findings and cervical biopsy. Kathmandu Univ Med J (KUMJ). 2007 Oct-Dec;5(4): 461-7.

20. Ranabhat, S. K., Shrestha, R., Tiwari, M. Analysis of abnormal epithelial lesions in cervical Pap smears in MidWestern Nepal. Journal of Pathology of Nepal 2011; 1, $30-33$

21. Khattak ST, Khattak I, Naheed T, Akhtar S, Jamal T. Detection of abnormal cervical cytology by pap smears. Gomal J Med Sci. 2006;4:74-7.

22. Pradhan N, Giri K, Rana A. Cervical cytology study in unhealthy and healthy looking cervix. $\mathrm{N}$ Obstet Gynaecol. 2007;2:42-7.

23. Kenneth DH, Yao SF. Cervical and vaginal cancer. In: Novak's Gynecology. 13th ed. Philadelphia: Lipincott Williams and Wilkins 2002;pp. 471-93.

24. Mulay K, Swain M, Patra S, Gowrishankar S. Comparative study of cervical smears in an Urban

\section{Original Research Article}

Hospital in India and a population based screening program in Mauritius. Indian J Pathol Microbiol 2009; 52:34-7.

25. Al Eyd GJ, Shaik RB. Rate of opportunistic pap smear screening and patterns of epithelial cell abnormalities in pap smears in ajman, United arab emirates. Sultan Qaboos Univ Med J. 2012 Nov; 12 (4): 473-8. Epub 2012 Nov 20.

26. Manjit Singh, Rishu Goyal et al. Detection of abnormal cervical cytology in Papanicolaou smears. J Cytol. 2012 Jan-Mar; 29 (1): 45-47.doi:10.4103/09709371. 93222.

27. Tripathi N, Kadam YR, Dhobale RV, Gore AD. Barriers for early detection of cancer amongst Indian rural women. South Asian J Cancer. 2014 Apr;3(2):122-7. doi: 10.4103/2278-330X.130449.

28. Kuhn L, Denny L, Pollack A, et al. Human papillomavirus DNA testing for cervical cancer screening in low-resource settings. J Natl Cancer Inst. 2000 May 17; 92 (10):818-25.

\section{How to cite this article?}

Singh A, N. Madhavi, Sukhavasi C. Prevalence and analysis of abnormal Pap smear: Prospective study of 752 patients in a tertiary care hospital of South India.Obs Rev:J obstet Gynecol 2018;4(3):67-72.doi:10.17511/joog.2018.i03.05. 